\title{
LA TEORÍA DE LA ACCIÓN COMUNICATIVA: CONSIDERACIONES CRÍTICAS AL PLANTEAMIENTO HABERMASIANO
}

\author{
THE THEORY OF COMMUNICATIVE ACTION: CRITICAL \\ CONSIDERATIONS TO THE HABERMASIAN APPROACH
}

\author{
Jovino Pizzi*
}

\begin{abstract}
Resumen
Con la teoría de la acción comunicativa, Habermas sostiene una fundamentación pragmático-normativa de la moral. Pero, a pesar de la potencialidad de su propuesta, esta teoría ha recibido muchas críticas. El artículo sostiene la necesidad de radicalizar aún más la propuesta de la acción comunicativa. Desde una noción de sujeto pronominal, es posible avanzar y garantizar también a las terceras personas una corresponsabilidad en la interacción comunicativa. El rechazo a la participación encarcela el sujeto a un monolingüismo estúpido, a una actitud egoísta y sin consideración a la convivencia social.
\end{abstract}

Palabras clave: Habermas, acción comunicativa, pragmática, sujeto pronominal.

\begin{abstract}
With the theory of communicative action, Habermas provides a pragmatic-normative foundation of morality. Despite the potential of his proposal, it has received lot of critics. The article points out the need to radicalize more the communication action proposal. From a notion of pronominal subject, it is possible to advance and guarantee too the third parties co-responsibility too in communicative interaction. The rejection of participation imprisons the subject to a stupid monolingualism, a selfish attitude and without any consideration for social coexistence.
\end{abstract}

Keywords: Habermas, communicative action, pragmatic, pronominal subject.

Recibido: 2020-09-25 Aceptado: 202I-05-09

* Doctor por la Universidad Jaume I, España. Profesor de la Universidad Federal de Pelotas, Brasil. E-Mail: Jovino.piz@gmail.com 


\section{Introducción}

Las consideraciones en torno a la teoría de la acción comunicativa de Habermas nos lleva a un diseño dibujado por Franca D'Agostini, en su libro Analíticos e continentais (versión brasileña del 2002), donde habla de "dos modos de concebir la praxis filosófica: una filosofía científica, fundamentada en la lógica, en los resultados de las ciencias naturales y exactas, y una filosofía de rango humanístico, que considera determinante la historia y piensa la lógica como arte del logos o materia del concepto, más allá del cálculo o algo computacional" (D’Agostini 2002, p. 22). En este diseño, Habermas es uno de los autores perteneciente al segundo grupo, por lo cual la idea de racionalidad comunicativa propone una "progresiva afirmación de la racionalidad en la vida social en todos sus aspectos" (D’Agostini 2002, p. 495). Por cierto, es posible afirmar distintas concepciones de razón. Fernando García (20I4) asegura que hay dos y una de ellas está directamente ligada al pensamiento postmetafísico de Habermas. De todos modos, se trata de la innovación de las "estructuras tradicionales", actitud que exige de la filosofía misma, un movimiento hacia la renovación, un "nuevo renacimiento" que provoca "rupturas" con alcances significativos (Habermas I990, p. I3).

En este sentido, Gérard Raulet subraya el giro pragmático habermasiano, cuyas pretensiones de validez exigen de los participantes consensos intersubjetivos entre todos. En este sentido, ha sido importante la "sustitución del paradigma del sujeto o de la conciencia por el del lenguaje" (Raulet 2009, p. 274). Con este cambio, la acción comunicativa requiere de los sujetos la interacción y el reconocimiento intersubjetivos, de forma de superar "la desintegración de los actos lingüísticos" a través de un proceso argumentativo racional (Raulet 2009, p. 28I).

El giro pragmático-filosófico ha tenido recepciones distintas, no solo dentro de Alemania, sino también en el contexto norteamericano y latinoamericano. Tal complejidad obedece a intereses de recepción o a preferencias individuales, a veces no tan claras, vinculadas a acercamientos individuales, de grupos de investigación o de perspectivas teóricas e, incluso, a coyunturas locales o intercontinentales. Por cierto, los movimientos de las ideas filosóficas no se limitan "a una serie de monografías sobre los sistemas de pensamiento", un tipo de abstracción de las problemáticas intelectuales y políticas, también hay un situs, es decir, ellos están siempre vinculados a "la situación de las corrientes del pensamiento en las coyunturas político-intelectuales (Raulet 2009, p. I2). 
En este sentido, la receptividad de los autores en los distintos países y universidades no puede ser un tema desechable. En otras palabras, no se trata de un interés meramente informativo, sino de adentrarse en el horizonte filosófico -y también de la vida práctica- de los debates, enfrentamientos y proposiciones, lo que implica identificar e intentar proponer soluciones a los problemas y dicotomías de la filosofía misma. No parece ser de la praxis filosófica señalar solo la fragmentación y apenas subrayar las disonancias, como si la filosofía haya llegado a su fin y, por eso mismo, no queda nada más sino resignarse.

Entonces, la pregunta dónde está la filosofía y -otra más- cuál sería su lugar y destino nos lleva a entender la filosofía como praxis, actitud que no se limita al estudio de autores y de sus textos, sino a la comprensión y discusión de análisis de problemas de nuestro tiempo. Por eso, la receptividad del pensamiento alemán en los distintos países de América Latina sería un tema importante. Sin embargo, para cumplir con el objetivo de este texto, me centro en el giro pragmático habermasiano, apuntando posibles limitaciones o alternativas a su planteamiento.

Con el fin de señalar las posibilidades de una radicalización de la perspectiva habermasiana, este texto empieza con el contexto donde el autor se sitúa, es decir, la segunda mitad del siglo XX. ${ }^{I}$ El segundo punto trata de la teoría de la acción comunicativa, un concepto clave para las pretensiones habermasianas. El tercer paso llama la atención a la radicalización de la teoría de la acción comunicativa, en el sentido de manifestar avances y, de este modo, corregir el excesivo procedimentalismo de la propuesta de Habermas. Se trata de reconocer quienes son los sujetos y cómo ellos pueden realmente consolidar una interacción comunicativa en su forma más intransigente.

\section{Habermas en el horizonte de la filosofía del siglo XX}

Las consideraciones a la teoría de la acción comunicativa exigen situar Habermas en el contexto del pensamiento filosófico del siglo XX. Se trata de un período con significativos movimientos y tendencias, tanto en el seno del pensamiento alemán como también en otros países y continentes. D'Agostini habla de expresiones como la "filosofía analítica, la

I La recepción del pensamiento alemán del Siglo XX en Brasil, por ejemplo, ha sido diseñada por Jorge de Almeida e Wolfgang Bader (2013). 
hermenéutica, la teoría crítica, el post-estructuralismo, la epistemología post-positivista" (2002, p. 30). Habermas sostiene que este período está marcado por "cuatro movimientos filosóficos fundamentales: la filosofía analítica, la fenomenología, el marxismo occidental y el estructuralismo" (I990, p. I4). Con influencias y "efectos" dentro y fuera de la academia, todos esos movimientos sostienen "diferencias nada desdeñables" $\mathrm{y}$, por eso, sus perfiles siguen ocupando un lugar destacado en el quehacer filosófico.

En general, hay una tendencia a estudiar esas "expresiones" como separadas unas de las otras, realzando enfrentamientos y disidencias. A veces, según la afiliación particular, hay predominancia o hegemonía -casi absoluta- de una línea o perspectiva filosófica, una actitud no tan saludable para el quehacer filosófico. Otras veces, esa misma perspectiva se centra en un pensador específico. Por ejemplo, si uno admira tal autor o sostiene sus vínculos, entonces nada o muy poco de sus déficits aparecen. En sentido contrario, el impulso está en destruir sus argumentaciones. Por ese motivo, la propuesta de este texto está en presentar, en líneas generales, a Habermas en el contexto de la filosofía del siglo XX para, entonces, entender posibles limitaciones de su planteamiento. De este modo, esta reflexión crítica no significa un rechazo al proyecto habermasiano, sino avanzar e intentar, de este modo, apuntar lo que se podría llamar correcciones a sus planteamientos.

Como punto de partida, es importante subrayar que "Alemania se sitúa en el centro de la historia del siglo XX" (Bader 2013, p. 9). ${ }^{2}$ Por este motivo, hay distintos modos o "entradas" para presentar el pensamiento de Habermas. En este momento, deseo subrayar dos aspectos introductorios importantes:

a) El primer punto remite a su vínculo con la Teoría Crítica de la Sociedad, de forma más amplia, a la segunda generación de la Escuela de Frankfurt (Raulet 2009, p. 268). Habermas ha sido asistente de Adorno, una inspiración que le permite entender la tradición alemana de la segunda mitad del siglo XX y, así, tener idea de la racionalización del mundo moderno. Sus consideraciones se centran en la crítica al cientificismo y al programa epistemológico volcado a la comprensión de los efectos del tecnicismo y del positivismo como justificación ideológica.

2 En relación al pensamiento de Habermas en Brasil, uno de los eventos importantes está ligado al Coloquio Habermas que, para 2020, llega a su XVI edición. Las publicaciones e informaciones están en https://coloquiohabermas.wordpress.com/ 
El hecho de separar y neutralizar tanto el conocimiento del interés, como de su vínculo con el mundo de la vida, y considerar cada uno de estos aspectos "como una realidad automizada", no pasa de ser una tentativa que burla "un nexo en realidad indisoluble". Por eso, subraya Habermas, "la reflexión acerca de tales intereses obliga a pensar dialécticamente" (I988, p. 44), procedimiento que hace posible la autoconciencia crítica y el esfuerzo por la emancipación respecto a las coacciones de la ciencia y de la propia naturaleza. De ahí, entonces, el esfuerzo por recuperar la comunicación libre de cualquier coacción, perspectiva que permitiría reconstruir el principio de la emancipación de las personas y de la sociedad a través del diálogo.

A través de la cooperación y la interdisciplinaridad de las ciencias, Habermas intenta rehabilitar la noción de racionalidad en torno a la multiplicidad de sus voces. Sus primeras obras, de modo especial Conocimiento e interés, retratan la historiografía sistemática de la argumentación, dentro de la cual parece no encontrar alternativas convincentes. En esta obra, Habermas intenta resolver su querella con el positivismo y con la filosofía analítica a través de una argumentación que se procesa dentro de los límites de una teoría del conocimiento. Esta arqueología de la tradición filosófica moderna, como también se podría llamar, permite a Habermas darse cuenta de las debilidades de una teoría del conocimiento que se aplica a la confrontación entre sujeto y objeto. El modelo de un conocimiento que se refiera al contraste entre sujeto-objeto queda estéril, pues no sólo trunca la conexión del saber teórico con la diversidad de presentaciones del mundo de la vida, sino que carece de una fundamentación capaz de liberar la propia filosofía de los límites de la filosofía de la conciencia.

El paso para una teoría comunicativa exige el abandono de la filosofía como lugar privilegiado, es decir, prescindir de la tradicional jerarquía entre las ciencias, de forma que la filosofía pase a asumir un lugar de intérprete. Se trata, pues, de exonerar la filosofía de su pretensión salvífica para, entonces, asegurarle su relación con la multiplicidad de discursos. Su papel se centra en la pretensión reconstructiva de los distintos saberes. De este modo, cada discurso ocupa su lugar específico y la filosofía tiene que "aclarar los fundamentos presumiblemente universales de la experiencia empírica y del juicio, de la acción y del entendimiento lingüístico mutuo" (Habermas I989, p. 30).

b) Eso ya sería tema de una larga discusión, pero hay un segundo aspecto fundamental para la teoría de la acción comunicativa: el concepto de Lebenswelt (mundo de la vida). La noción de mundo de la 
vida ${ }^{3}$ reanuda y reformula el planteamiento de Husserl, para transformarla en una categoría clave para la comprensión de los aspectos contra-fácticos de la fundamentación discursiva. Se trata, pues, de "una interpretación específica, vinculada con la recuperación del programa fenomenológico del conocimiento para un programa de la teoría crítica en el ámbito de las ciencias sociales" (Salas Astrain 2006, p. 19). Por eso, Habermas habla de la "constitución del mundo", de un contexto de la vida y de una forma de vida que "no puede ser negada" (I982, p. 26). Se trata, pues, de una categoría fundamental para entender la configuración de su planteamiento teórico, porque el Lebenswelt está presente como el trasfondo de la acción comunicativa.

En su estructura, el mundo de la vida se divide en tres horizontes: objetivo, subjetivo e intersubjetivo. A cada uno de ellos le corresponde determinadas pretensiones de validez, con sus posibilidades comprensivas:

a) el mundo objetivo está implicado con pretensiones de verdad, con lo cual los sujetos tratan de conocer las situaciones y acontecimientos en el mundo físico;

b) el mundo subjetivo, que trata del aspecto interior de los sujetos, donde uno y solamente uno mismo tiene acceso privilegiado;

c) y el mundo intersubjetivo, de la interacción social, en el cual los sujetos establecen un vínculo relacional, es decir, una exigencia de orden normativa.

En este sentido, uno puede entender también la tipología de la acción. Las acciones instrumentales indican el vínculo con el mundo objetivo, mientras las acciones comunicativas ocurren entre sujetos participantes. Esa distinción es importante, pues permite distinguir lo que sería una relación sujeto-objeto, muy distinto de lo que representa una intersubjetividad sujeto-sujeto. En este punto entendemos la posibilidad de una perspectiva normativa, pues se trata de fundamentar las interacciones desde un punto de vista moral. De ahí nace la noción de acción comunicativa, pues se trata de la intersubjetividad entre sujetos-sujetos.

En un primer momento, el mundo de la vida designa el horizonte pre-teórico que permanece siempre a las espaldas; en sus últimos textos, los distintos contextos del mundo de la vida "siguen formando la caja de resonancia de todos los costes externos que los sistemas funciona-

3 Este ha sido el tema de mí tesis doctoral y parte de la tesis ha sido publicada como libro por la Editorial de la Universidad Católica Silva Henríquez (primera edición en 2005 y una segunda edición (ampliada) en 2016). 
les cargan sobre las biografías de sus clientes" (Habermas 20I5, p. 206). Como "caja de resonancia", el Lebenswelt remite a un quehacer filosófico comprometido con la situación fáctica de un mundo multicultural e intercultural. En otras palabras, la "unidad de la razón en la multiplicidad de sus voces" (Habermas 1990, p. 155). Como resume Salas Astrain, Habermas trata de comprender las "condiciones de una reconstrucción de los presupuestos de la racionalidad social" (2006, p. 19). No se trata, pues, de una reflexión abstracta, ajena o con un carácter metafísico. Ejemplo de tal compromiso son sus dos obras Pensamiento post-metafísico, ${ }^{4}$ textos volcados al diagnóstico de nuestros tiempos y las implicaciones de la acción comunicativa en la crítica social.

Para ilustrar esos aspectos del pensamiento de Habermas, Axel Honneth -en el libro La sociedad del desprecio, capítulo 3- subraya un punto importante de la filosofía europea. Honneth indica dos tendencias (internas) de la filosofía: una ligada a la "crítica social negativa" y otra en el sentido contrario. Como se ha destacado, D'Agostini y Ralulet también presentan un diseño cercano. De entre los negativistas está la primera generación de la Escuela de Frankfurt y, entre otros, los franceses Foucault y Baudrillard. La corriente que "representa un movimiento contrario a las teorías sociales negativistas" ha abierto de nuevo, dice Honneth, "el acceso a una esfera emancipatoria de la acción" (Honneth 20II, p. 132).

En la interpretación de Honneth, se trata de "la reorientación del paradigma marxista de la producción al paradigma de la acción comunicativa, en cuyo marco debe ser evidente que la condición para el progreso social no está establecida por el trabajo social sino por la interacción social" (Honneth 20II, p. I32). Ese cambio significa, pues, el desarrollo de una pragmática del lenguaje volcada a aclarar cuáles son las condiciones normativas de la racionalidad ético-comunicativa. Es decir, una teoría del lenguaje volcada a reconstruir las condiciones de una intersubjetividad comunicativa. En un contexto de acción y en el horizonte del mundo de la vida, esa apertura a la "situación fáctica" posibilita no solo entender las luchas por emancipación, sino también identificar las patologías sociales y sus efectos nefastos sobre las interacciones y la convivencia. En otras palabras, la amplitud de la racionalidad vinculada a las formas de vida y a las experiencias prácticas del convivir.

4 Nachmetaphysiches Denken es el título original de un libro publicado en Alemania en 1988, y traducido al castellano como "Pensamiento postmetafísico" (Taurus, 1990). En 2012 sale otro libro con el título Nachmetaphysiches Denken II: Aufsätze und Repliken (Suhkamp Verlag, Berlín). Este último ha sido traducido al castellano por Jorge Seca y publicado por Trotta (2015), cuyo título es: Mundo de la vida, política y religión. 
En este grupo, preocupado con la racionalidad práctica y la corresponsabilidad social, están Habermas, Honneth, Rainer Forst ${ }^{5}$-apenas para mencionar algunos. Según Habermas, existen tres momentos distintos en la filosofía: la era del ser, la era de la conciencia y la era del lenguaje. Con su obra Teoría de la acción comunicativa, Habermas consolida entonces el giro pragmático de la filosofía, lo que significa el abandono de la filosofía de la conciencia. El lenguaje pasa a ser el médium que permite integrar las diferentes perspectivas de la acción. El linguist turn significa, pues, el pasaje de la semántica a la pragmática (Raulet 2009, p. 269), aspecto fundamental para la teoría de la acción comunicativa.

\section{La Teoría de la acción comunicativa habermasiana}

El eje central de Habermas está en la noción de acción comunicativa. Ella representa un paso sin igual en la crítica al positivismo y a la neutralidad de las ciencias para, de este modo, intentar superar las debilidades de una racionalidad menguada. Uno de los puntos de mayor relevancia está en su capacidad de romper con el entramado del solipsismo metodológico, un cambio que modifica el status tradicional de la filosofía. Habermas defiende criterios universales en una época en que los estilos de pensamiento relativistas se han puesto de moda. Para el autor, la racionalidad comunicativa "tiene la ventaja de que evita un individualismo que se introduce subrepticiamente entre las premisas de la filosofía del sujeto" (Habermas 200o, p. 173). Esas consideraciones nos llevan a las diferencias de perspectivas que tal cambio sostiene.

De manera muy sencilla, hay cuatro aspectos relacionados entre sí: a) la propuesta de un "nuevo" concepto de razón, que -así como lo entiende Habermas- no deseche el sentido de la práctica cotidiana y de las formas de vida inherentes a las experiencias prácticas; b) la distinción entre la actitud del observador y del participante, una idea que atestigua la diferencia entre dos perspectivas distintas, pues una teoría de la acción supone una comprensión, a la que no se pude acceder sólo por vía de la observación; c) en tercer lugar, el abandono del paradigma de la conciencia, sustituyéndolo por el paradigma de la comunicación. Ese aspecto es vital para la teoría de la acción comunicativa y, por ende, para las intenciones

5 Por ejemplo, la recepción chilena del pensamiento de Forst aparece en Ricardo Salas Astrain. Uno de sus artículos es "Justicia universal, contextos asimétricos del poder y pensamiento crítico latino-americano", publicado en la Revista Estudios, A. 24, Extra I, 2019, p. I6-27. 
de este trabajo, que son de identificar la aportación de la Lebenswelt para la comprensión de un concepto de racionalidad capaz de dar razón a las estructuras universales que subyacen a la acción humana; d) y, por último, la dudosa capacidad de análisis de las teorías del significado, motivo por lo cual Habermas insiste en el giro lingüístico, fundamentalmente en el uso pragmático del lenguaje.

La alternativa reconstructiva supone un horizonte de la vida cotidiana y la posibilidad de idealización. De forma muy simple, cuando los sujetos, en la comunidad real de comunicación, discrepan acerca de los principios, ellos deben suponer una comunidad ideal de comunicación, en donde buscan, a través de argumentos, el consenso con validez para todos. Ese sería el procedimiento reconstructivo, o sea, una metodología que permite a los participantes lleguen a un consenso sobre las pretensiones de validez aceptas por todos. Esa validez asume un carácter casi transcendental, pues ella puede ser puesta en duda en cualquier momento. De este modo, Habermas supone que toda y cualquier pretensión de validez puede ser criticada y así pasar por una nueva revisión.

Entonces, sin desear sobreestimar el giro lingüístico, "su innegable realidad consiste" en replantear un modelo de ciencia crítica de forma que la pragmática universal "abarque de manera general las condiciones de posibilidad del acuerdo lingüístico". Esta base teórica "sirve para explicar las comunicaciones sistemáticamente deformadas y los procesos de socialización marginales" (Raulet 2009, p. 269).

En su fundamentación, Habermas asume un carácter universalista, reformulando el imperativo categórico kantiano. El lenguaje aparece como médium a través de cual los participantes pueden llegar al consenso. De pronto, el consenso se torna un aspecto fundamental en Habermas, al tiempo que las reacciones también son significativas. Entonces, para Habermas, el consenso funciona como un paso más allá de las contrariedades, es decir, de las situaciones de disenso o disentimiento, porque, en caso de disenso, no hay una pretensión de validez común. En otras palabras, la desintegración de la fuerza obligatoria de las éticas ha hecho que la moral post-tradicional permanezca limitada en la simple conciencia moral de cada uno (Raulet 2009, p. 279). Así, no queda otro remedio sino al procedimiento que permita buscar un consenso entre aspectos factuales y contra-factuales.

A su turno, la acción comunicativa se centra en la relación intersubjetiva entre todos los sujetos. Para evitar la coerción o la violencia, Habermas insiste en la complementariedad entre habla y acción. El uso pragmático del lenguaje está vinculado a los actos de habla como unidad 
elemental de la comunicación. Tal uso del lenguaje abre camino hacia la reconstrucción del núcleo universal del habla, no a partir del langue, sino del uso performativo (parole). Por eso, los actos de habla presentan un doble aspecto: la oración principal y otra subordinada. El contenido proposicional se encuentra en la oración subordinada ('_ q $p$ '), que cumple el sintagma nominal frente a la principal. En la estructura de la acción comunicativa, el componente 'p' designa una situación en el mundo objetivo, que en la emisión se halla o se producirá manteniendo constantes determinadas condiciones. La oración principal supone un sujeto que se sitúa frente a otro sujeto, pues la fuerza ilocucionaria del acto de habla consiste, pues, en comprender el contenido emitido. La oración principal indica que Ego se dirige a Alter, asumiendo su condición de sujeto-actor. Este sujeto, al emitir un acto de habla, está imbricado frente a otros sujetos, pues se trata de una interacción intersubjetiva.

La intersubjetivad comunicativa representa, pues, esa relación en donde ego y alter ego están frente a frente, y utilizan el lenguaje para llegar a un consenso sobre algo relacionado al mundo de la vida. Por eso, siempre y cuando aparece un disenso, los participantes sustraen temporalmente sus concepciones y buscan, en el nivel contra-fáctico, un denominador común válido para todos. El carácter racional se vincula al compromiso ilocucionario, de forma que hablantes y oyentes expresen sus propuestas en la primera persona del presente, con el fin de establecer un vínculo normativo. La posibilidad de acuerdos válidos y legítimos representa, entonces, un punto fundamental en la conexión entre la fundamentación racional y la pluralidad de formas de vida, al tiempo que garantiza la participación de los interesados en las normas y principios.

\section{Algunas reacciones y posibilidades de avances}

Esta perspectiva suscita reacciones importantes. Un punto importante trata de la noción de un transcendentalismo debilitado (mitigado), es decir, del carácter casi-transcendental del consenso, una noción contra-factual en constante revisión. Para Richard Rorty, por ejemplo, esa idea solo es posible en las aserciones, y nunca en la justificación y la verdad (Raulet 2009, p. 279). De este modo, las proposiciones se relacionan a afirmaciones en torno de algo en el mundo de la vida, sin, por eso, encontrar un consenso mutuo en torno a la diversidad de situaciones concernientes al mundo de la vida. Y cuando no hay consenso entre los sujetos, solamente el derecho podría constituirse en la instancia de mediación entre el mundo de la vida y los sistemas sociales. En este caso, el 
derecho funciona como "instancia de mediación" capaz de frenar la desintegración social y política (Raulet 2009, p. 279). Por tanto, el derecho asume la coordinación de las acciones.

En el seno de este debate, Honneth entiende que hay otro aspecto sin un tratamiento adecuado. Se trata de la cuestión del poder, es decir, "el nacimiento de la dominación y, con ello, de la legitimación del poder" (2008, p. 36I). En la interpretación de Honneth, la pragmática de Habermas reduce las justificaciones normativas a "aquellas reglas lingüísticas que sirven de base para la acción comunicativa [que] poseen un carácter normativo en tanto que establecen, al mismo tiempo, las condiciones de un entendimiento libre de dominio" (Honneth 20II, p. I35). En este caso, los "grupos circunstancialmente en desventaja deberían estar dispuestos a aceptar el sistema establecido de poder y privilegios" (Honneth 2008, p. 36I). La respuesta de Habermas subraya que el entendimiento intersubjetivo es clave, de modo que el "poder comunicativo" se impone como un hecho normativo, un proceso que asume la forma de un acuerdo intersubjetivo acerca de las normas sociales.

A su vez, Honneth entiende que los mecanismos o factores motivacionales quedan subsumidos, o sea, el poder asimétrico de cargas y ventajas representa una fuerza que moldea y conforma las condiciones institucionales de las relaciones sociales. Para Honneth, una teoría que tiene la pretensión de establecer normas a la convivialidad tiene que suponer el conflicto. Es decir, "las condiciones planteadas por la división desigual de las cargas y privilegios" exige modos de organizar la praxis considerando la "lucha social" entre sujetos participantes (Honneth 2008, p. 397). Sin esta perspectiva, "la investigación de las estructuras básicas de la intersubjetividad quedará reducida a un análisis de las reglas lingüísticas" (Honneth 2008, p. 4I3).

Más detalladamente, la pragmática universal "ha seguido un camino que lleva al punto de equiparar el potencial normativo de la interacción social con las condiciones lingüísticas de un entendimiento sin dominio" (Honneth 20II, p. 135). En este sentido, la conclusión de Honneth es: "cuanto más grandes son las ventajas que acompañan a semejante versión teórico-lingüística del paradigma de comunicación, tanto más graves son, por el contrario, las desventajas que están relacionadas internamente con ella" (Honneth 20II, p. I35).

El despliegue teórico de Honneth cambia la noción de consenso e introduce una gramática del conflicto moral. No es el momento para entrar en esa discusión, porque las consideraciones a la acción comunicativa remiten también a una gramática del sujeto pronominal. Aquí 
está mi contribución, lo que significa, en otras palabras, una radicalización del planteamiento de Habermas, una actitud que corrige el excesivo procedimentalismo para, entonces, señalar e identificar quienes realmente son los sujetos y cómo ellos deben ser reconocidos como sujetos pertenecientes a un determinado grupo social, género y cultura. Es decir, ellos nutren un estilo de vida, con cargas, ventajas o menosprecios que no pueden ser desechados. Mi sugerencia centra la perspectiva en el participante como sujeto coautor.

Por este motivo, el uso de las formas pronominales indica un proceso interactivo en donde el sujeto no permanece absorbido en el universalismo formal o desaparecido en un transcendentalismo argumentativo. La interacción entre los sujetos está directamente relacionada a las características particulares de cada sujeto o grupo y, además, a la forma en cómo los pronombres personales son utilizados. Por eso, cualquier manifestación utiliza un pronombre personal en un contexto de experiencias compartidas intersubjetivamente. Esa experiencia se vincula pues al reconocimiento concerniente al uso de los diferentes pronombres personales, sin que haya supremacía de uno de ellos y, entonces, un "determinado" menosprecio o disminución de algunos de ellos. Se trata de una arquitectura pronominal o de una gramática comunicativa en la forma de una equidad o, quizá, de simetría entre todos los pronombres personales en consonancia con la utilización de los pronombres verbales.

De ahí, entonces, la exigencia de una gramática del sujeto pronominal, la cual presume una comunidad de comunicación en donde cada pronombre posee voz activa. Por un lado, la equidad entre los pronombres personales (singular y plural) representa, por sí misma, una condición para la acción comunicativa y, a través de eso, asegurar la certificación de quienes son de hecho los sujetos participantes. Por otro, esa consideración evita que ninguno de los pronombres personales pre-enuncie un significado o represente el indicio de ser, presumiblemente, neutro, o sea, indefinido y, por tanto, ajeno.

En casos más extremos, el uso de la tercera persona (singular o plural) podría remitir a un sujeto absolutamente indeseado. En ese sentido, el uso de la tercera persona (él o ellos, según el caso) podría subrayar la especificación de adjetivos a individuos reconocidos como nadies y, así, indicar o hacer referencia a sujetos que son simple andadores o pobres, marginalizados del sistema, prófugos, refugiados, clandestinos, indocumentados, esclavos, deportados y puede llegar, incluso, al nivel de terroristas y anti-sociales. En este sentido, el "poder comunicativo" no está vinculado al uso del lenguaje, pues depende también de la situación so- 
cial o de grupos calificados como vulnerables, designados, por tanto, a través del pronombre en la tercera persona (singular o plural). Evidentemente, esa vulnerabilidad exige un reconocimiento de su situación y de sus necesidades, aspecto que la teoría de la acción comunicativa supone, pero no garantiza por completo, frente a las posibilidades de dominación, sumisión o de colonización.

Por eso, el núcleo de la gramática pronominal del sujeto coautor -como la que se pretende defender-parte del presupuesto de que la teoría de la acción comunicativa necesita de una radicalización, es decir, un paso más al diseño procedimental habermasiano. Ese movimiento no significa el abandono de sus premisas esenciales. Se trata, entonces, de hacer figurar quienes son los sujetos de la acción y, además, cómo ellos se presentan en todas sus formas pronominales. De este modo, pertenecen a la comunidad de comunicación no solamente las primeras y segundas personas (singular o plural), o sea, ego y alter ego, sino también la tercera persona. No pocas veces, la tercera persona designa un sujeto neutral y ajeno, por lo cual no entra en lo que Habermas supone cuando habla de ego y de alter ego.

La nueva configuración no significa una simple designación gramatical, porque no se trata de sus unidades, categorías, relaciones y funciones sintácticas. Al utilizar la noción de acción comunicativa, las exigencias de reconocimiento y el modelo deliberativo, presupone un tratamiento equitativo de todas las personas pronominales, a los sujetos sin ninguna enajenación. Esa gramática pronominal exige, pues, la garantía del reconocimiento comunicativo a todos los pronombres, cuyo tratamiento pronominal certifica a los sujetos como coautores, independiente de la capacidad comunicativa e interactiva y de su situación social. Entonces, esa experiencia práctica, concerniente a los sujetos pronominales está ligada a la alternancia de roles, un proceso en lo cual los sujetos aseguran la distinción pronominal entre pronombres, tiempos y formas verbales, sin ninguna separación entre el pronombre personal y el verbo.

Habermas, en su teoría de la acción comunicativa insiste en la relación intersubjetiva, intercalando ego y alter ego, es decir, el aspecto dialógico entre hablante y oyente (singular o plural). Esa sería la configuración básica de la comunidad real de comunicación, sea en su ámbito fáctico o contrafáctico. Al traducir ese aspecto binomial, aparece siempre la referencia a una interacción entre dos sujetos, cuyo eje gravitacional pone frente a frente ego y alter ego. En la interacción, ego está ante a alter ego, o sea, la locución pronominal es alter ego -y no simplemente ego. Al contrario, prevalece una noción de alteridad indefinida. 
Según mí interpretación, ese diseño binominal ego versus alter ego no alcanza el nivel radical de la interacción entre sujetos coautores, porque gramáticamente hablando, además de ego y alter, hay otros pronombres personales. Jean Marc Ferry también subraya la noción de mundo de la vida, pero dándole otra dimensión, es decir, introduciendo la noción de sujetos pronominales y, así, haciendo figurar los sujetos en todas sus representaciones pronominales. La noción de Ferry amplía la representación de tres mundos, sin limitarse al aspecto binomial entre ego y alter ego. Por eso, en su versión de comunidad de comunicación, el autor francés alude a "cuatro dimensiones: a las tres referencias relacionadas al él, al tú y al yo, pero que, al final, se desplaza a un nosotros". Para realzar aún más su diseño, Ferry afirma: "solamente en este campo se podrá saber por qué una proposición es verdadera, en el pleno sentido de una relevancia ontológica de nuestras relaciones con el mundo entre los sujetos mismos" (Ferry I99I, p. I87).

En este sentido, la interacción entre los sujetos coautores presupone la alternancia de roles entre sujetos pronominales de las diferentes personas, con lo cual la consideración equitativa de todos los pronombres personales pasa a ser fundamental. Esa perspectiva reequilibra las distorsiones en el tratamiento personal, cuyo reconocimiento puede ocurrir, pero sin garantizar su pleno status de sujeto coautor.

Habermas permanece en el aspecto binominal entre hablante y oyente, o sea, entre ego y alter ego. Sin embargo, la noción de sujeto pronominal involucra también a los demás pronombres personales. Por eso, las cuatro dimensiones diseñadas por Jean Marc Ferry sostienen un abanico más amplio, para incluir, por lo menos, cuatro pronombres personales. Por eso, al tratarse de verdad, de la justicia y de la significación individual, el "centro gravitacional está siempre en el nosotros" (Ferry, I991, p. 190), sin eximir la multiplicidad de otros pronombres personales. Ese nosotros representa la comunidad siempre ilimitada de comunicación, en la cual los sujetos coautores desempeñan sus performatividades y actúan en vistas a la acción comunicativa.

No pocas veces, en los idiomas latinos, la designación él o ellos indica persona o grupos ajenos, es decir, desechables. No pocas veces, el simple tono de voz o la gestualidad puede indicar una designación peyorativa. De mi punto de vista, la radicalización de la acción comunicativa podría entonces asegurar un tratamiento pronominal a cualquier sujeto coautor, de manera de reconocer tanto el hablante (singular o plural = yo o nosotros) como también el oyente (singular o plural = tú o vosotros), concediéndoles el status de sujeto coautor, de forma de sustituir el as- 
pecto bidimensional por el horizonte del nosotros. Aun cuando el sujeto pronominal sea utilizado en las terceras personas, la designación supone siempre una comunidad de comunicación en la cual el nosotros no excusa o recusa cualquier acto de habla, y asimismo cuando el pronombre personal sea utilizado en la tercera persona (singular o plural).

Por fin, un último aspecto relacionado al sujeto pronominal. Se trata de quienes no aceptan o se excluyen del proceso comunicativo. Las condiciones universales podrían suponer que uno o cualquiera no desee aceptar las exigencias o las presuposiciones de pertenecer a la comunidad de comunicación. O sea, declare o manifieste un tipo de "insociabilidad", por lo cual se encaja como participante neutral y ajeno a la comunidad de comunicación. En este caso, se podría pensar que la exclusión sea voluntaria o, entonces, provocada por el sistema.

El sujeto, al declarar su exclusión, niega la condición de participante y de coautoría para adoptar una actitud solipsista, a fin de rechazar cualquier posibilidad de participación. Tal actitud indica una forma de necrofilia (Fromm 1980), es decir, representa ser una persona "fría, distante" y con una perspectiva ajena a la interacción; en fin, una actitud volcada a la muerte y destrucción de la colectividad. No se trata solamente de un aspecto psicológico, sino de una actitud frente a los demás, cuyo poder está volcado a la violencia, o sea, en contra todo lo que indica reconstrucción.

Esa actitud negativa sostiene un necropoder nefasto, es decir, una actitud que representa la sumisión y la exigencia de sometimiento de todos a la voluntad de uno. Al fin, sus potencialidades se transforman en artificios para un sistema de dominación, actitud que presume a los demás como sin vida o sin vitalidad. En este sentido, este sujeto monológico cree que solamente sus pretensiones se sostienen y nadie más puede pretender validez o plausibilidad a sus actos de habla. En tiempos de pandemia, por ejemplo, la presuposición artificial de ese tipo de individuo no tendría cómo sostenerse, pues las condiciones externas le imponen condiciones que, desde su mundo particular, no puede cumplirlas.

En el caso de la exclusión sistémica, la voluntad individual no depende del sujeto mismo, sino que pasa a estar conformada por el poder de un sistema que domina las voluntades. El necropoder refleja esa tendencia social o el impulso alimentado por la sumisión, o sea, una rutina de vida sin intereses, un ordenamiento mecanicista y en la completa sumisión al sistema (Fromm 1965, p. 56). Al final, se trata de un impulso muy negativo, de indiferencia y sin proposiciones para vivir en la cordialidad y de forma hospitalaria. 
La atmósfera cercana al necropoder es la ideal para el rebrote de movimientos sociales radicales basados en la xenofobia, la aporofobia, la discriminación y el rechazo de los indeseados. Se trata de ideas propagandísticas vinculadas a un tipo de eugenesia social por las cuales se supone que la sociedad podría y debería librarse de quienes son simplemente tratados como nadies (Pizzi 20I8). No se trata simplemente de una subvaloración de los otros, sino de un ostensivo desdeño de los más humildes, pobres y desaventajados de la escala social, que se contrapone a los que merecen homenajes, prerrogativas y recompensas, es decir, a los afortunados.

Desgraciadamente, esa forma de menosprecio hacia extensas capas de la población sostiene el décimo superior de la pirámide social, a todos aquellos afortunados que pueden disfrutar del despilfarro sin importarles si las demás clases sociales no tienen lo mínimo para vivir. En suma, es una forma de seguir excluyendo a quienes pertenecen al mundo de la tercera persona, porque prosigue un presentimiento de que la tercera persona (singular o plural) designa sujetos neutrales y, por tanto, que no cuentan y no valen, y son ajenos o en oposición a quienes detentan el mando, el poder y los instrumentos para la dominación. En este sentido, el tratamiento pronominal desde la tercera persona puede significar un proceso de eugenesia social en vistas a desechar a todos aquellos que pertenecen a estos grupos.

\section{Conclusión}

El siglo XX ha revelado una serie de movimientos o expresiones filosóficas de gran calado. La complejidad concierne a la dialogicidad entre ellas, pues ningún de los pensadores ha conseguido suficientes argumentos para crear teorías autosuficientes y con pretensiones monopolistas. Todas las expresiones son fruto de diálogos entre autores y tendencias. Por eso, comprender un autor significa entender sus vínculos y las recepciones en los distintos lugares, un trabajo a veces no tan sencillo. Al mismo tiempo, ahí está la fertilidad de una época. En un mundo cada vez más complejo, el quehacer filosófico reanuda su papel y se transforma en un saber práctico capaz de señalar alternativas a las patologías de nuestros tiempos.

En este horizonte, Habermas aparece como un pensador en sintonía y comprometido con su tiempo. El linguist turn representa, entonces, una alternativa filosófica. A él, le han colgado muchas etiquetas. Y un tiempo en que no se necesitan héroes o antihéroes, la posibilidad de dia- 
logar y sostener una perspectiva intersubjetiva ya es un hecho filosófico considerable. En este sentido, no cabe duda de que el estudio del pensamiento filosófico del siglo XX exige acercarse también a Habermas y a los alcances y posibles déficits de teoría de la acción comunicativa.

Como hemos visto, la reflexión crítica representa un primer paso para restaurar una "razón que ha quedado sin sujeto". Este es seguramente el motivo que incita a retomar el debate en torno a un concepto de racionalidad que pueda fundamentar normas válidas para todos, sin perder de vista los múltiples contextos y formas de vida de ese gran mosaico que representa la Lebenswelt. Si, por un lado, la fenomenología de Husserl sugiere un concepto de constitución del mundo, por otro, los intereses de la razón situada exigen liberarse de la teoría del conocimiento planteada en términos de constitución lógico-objetivistas y, entonces, postular por la pragmática del lenguaje que a nativitate se extiende a las interacciones lingüísticamente medidas. Como hemos mencionado, eso demanda un razonamiento que no se agote en el acto de entendimiento efectuado bajo procesos observables. El entramado historiográfico y, por supuesto, las sospechas de Habermas en torno a la filosofía de la conciencia ha mostrado la necesidad de un giro hacia la racionalidad comunicativa. De este modo, el entendimiento puede apoyarse al mismo tiempo en un saber proposicional intersubjetivamente compartido, en una coincidencia normativa y en la confianza recíproca. Estaríamos hablando de un concepto de una interacción social libre de las "patologías del mundo de la vida inducidas sistemáticamente".

El giro habermasiano ha dejado claro que no se puede dogmatizar la creencia en una fundamentación en las ciencias mismas. La racionalidad comunicativa presume "ver de otro modo" la validez de los enunciados normativos de la explicación teórica de los hechos. El giro lingüístico permite rehacer las consideraciones en torno al conjunto de la vida, pues las referencias sobre "algo" van más allá de las determinaciones de la coherencia sintáctica de los enunciados. De esto hemos deducido que cualquier tentativa de reorganizar los contextos comunicativos de la acción exige una racionalidad capaz de garantizar la acción moral y política de los distintos individuos y, al mismo tiempo, de la sociedad en su conjunto. 


\section{Referencias bibliográficas}

Almeida, J. de; Bader, W. (2013). O pensamento alemão no século XX. V. I: São Paulo, Cosac Naify.

D’Agostini, F. (2002). Analíticos e continentais. São Leopoldo: Editora Unisinos.

Ferry, J.M. (1980). El corazón del hombre. 7 ed., México: Fondo de Cultura Económica.

Fromm, E. (1965). O coração do homem. Rio de Janeiro: Zahar.

García, J. F. (20I4). "Habermas: referencia, verdade y motivos del pensamento postmetafísico". Revista de Filosofía, 70, nov. 2014.

Habermas, J. (1982). Conocimiento e interés. Madrid: Taurus.

(1989). Teoría de la acción comunicativa: Complementes y estudios previos. Madrid: Cátedra.

(1990). Pensamiento postmetafísico. Madrid: Taurus. (2015). Mundo de la vida, política y religión. Madrid: Trotta.

Honneth, A. (2008). Crítica del poder. Madrid: Antonio Machado Libros. (20II). La sociedad del desprecio. Madrid: Trotta.

Pizzi, J. (1994). Ética do discurso. A racionalidade ético-comunicativa. Porto Alegre: EDIPUCRS.

- (2005). O conteúdo moral do agir comunicativo. São Leopoldo: Editora Unisinos.

- (2016). El mundo de la vida. Husserl y Habermas. 2 ed., Santiago de Chile: Ediciones Universidad Católica Silva Henríquez.

(2018). "Democracias bajo efectos clikcbait. La gramática pronominal como respuesta a la virtualidad tecnocrática”. Veritas. Revista de Filosofía y Teología. 39:33-53.

Raulet, G. (2009). La filosofía alemana después de 1945. Valencia: Universitad de Valencia.

Salas Astrain, R. (2006). "Epistemología y pre-comprensión de la experiencia socio-histórica”. Cuadernos de Aula, N. 5, Ediciones UCSH. 